\title{
Passive smoking aboard passenger aircraft ${ }^{\star}$
}

\author{
Burckhard Junge
}

\begin{abstract}
A review of the relevant literature on measurements of tobacco smoke constituents in aircraft and other closed environments reveals that being seated in the non-smoking section of an aircraft does not provide effective protection against the involuntary inhalation of tobacco smoke. In certain instances, smoke concentrations higher than the average level in the smoking section may be present. Particularly in the borderline area between the smoking and nonsmoking sections (ie, one to three rows in front of or behind a smoking section), levels may be equal to or above those in the smoking section. This is particularly the case where ventilation makes partial use of recirculated air.
\end{abstract}

Pollutant concentrations from tobacco smoke aboard aircraft in smoking sections and the bordering non-smoking sections in part clearly exceed the levels in other indoor situations where smoking takes place. Levels in the non-smoking sections of aircraft (beyond the areas bordering smoking sections) are similar to those in homes where smoking takes place. In the majority of studies, health risks associated with passive smoking have been found in persons living in smokers' households.

Although exposure of the average air passenger lasts only for a comparatively short period, damage to health from such passive smoking should be principally the same, although clearly of a lesser impact, as in persons continuously exposed to tobacco smoke at home or at the workplace. The concentrations measured may cause an impairment of well-being and an elevated health risk for children, pregnant women, persons with a high susceptibility to tobacco smoke, frequent flyers, and especially cabin staff.

(Tobacco Control 1994; 3: 50-58)

* Dedicated to Professor Dr Hans Hoffmeister, Head, Institute for Social Medicine and

Epidemiology on the occasion of his 60 th birthday, with gratitude for almost 25 years of pleasant and fruitful

cooperation.

Presented in part at the 41 st International Congress on Aviation and Space Medicine, Hamburg, Germany, 12-16 September 1993 sections and ventilation systems are reported to remove the tobacco smoke which is produced. Yet tobacco smoke causes discomfort to the overwhelming majority of passengers and cabin crew. This discomfort may be related to the fact that modern aircraft are no longer ventilated with fresh air alone but with a considerable proportion of recirculated air (in order to save energy and costs).

\section{Tobacco smoke aboard aircraft}

Attempts have been made in a number of studies to determine tobacco smoke concentrations in aircraft cabins by measuring various components such as nicotine, carbon monoxide (CO), and respirable suspended particles (RSP). In addition, tobacco smoke components have been determined in body fluids sampled from passengers and flight attendants. The available studies are reviewed and discussed below in chronological order by the year of publication.

Initial studies were conducted as early as 1970/71 in the US $^{1}$ and 1977 in France. ${ }^{2}$ However, the results of these studies are of little use today because at that time, cabins were not subdivided into smoking and nonsmoking sections.

In 1983, Foliart et $a l^{3}$ collected and analysed blood and urine from six female flight attendants working aboard aircraft on the San Francisco-Tokyo route. Carboxyhaemoglobin levels remained practically unchanged at $1.0 \pm$ $0.2 \%$ (mean $\pm \mathrm{SD}$ ) prior to the flight and $0.7 \pm 0.2 \%$ following it. However, the nicotine level in blood rose significantly $(\mathrm{p}<0.05)$ from $1.6 \pm 0.8 \mathrm{ng} / \mathrm{ml}$ (range $0.8-2.7$ ) to $3.2 \pm$ $1.0 \mathrm{ng} / \mathrm{ml}$ (range 1.6-4.5). The authors compared these levels to concentrations detected in typical smokers $(15-45 \mathrm{ng} / \mathrm{ml}$ according to previously published data) and considered the former to be extremely low. They concluded that although nicotine intake had occurred among non-smoking flight attendants, the amounts, which were equivalent to one cigarette, were relatively small compared to the amounts taken up by smokers.

Comment: Although this conclusion has frequently been drawn and reiterated in other studies cited below, it is incorrect, because a non-smoker who has passively inhaled tobacco smoke should have been compared with a non-smoker not exposed to tobacco smoke. Such a comparison would reveal that the blood nicotine concentration of the exposed non-smoker has doubled as a consequence of tobacco smoke exposure in an indoor environment.

In 1987, Oldaker and Conrad ${ }^{4}$ from the $\mathbf{R} \mathrm{J}$ Reynolds Tobacco Company, studied cabin nicotine levels during flights of approximately one hour duration in aircraft of three different types, Boeing B 727-200, B 737-200, and B $737-300$. In the third aircraft type, $40 \%$ of air 
in the cabin consisted of recirculated air which was passed through a pre-filter and a fine filter (95\% efficiency for $0.3 \mu \mathrm{m}$ particle size) to remove RSP. Ventilation in the other two aircraft types did not use recirculated air. In all three types, the ventilation rate was high, with about 25 air changes per hour. Twenty-six measurements were taken in the smoking sections and 49 in the non-smoking sections. Of the latter, 40 were taken in the boundary region (ie, in the two rows adjacent to the smoking sections). The numbers of cigarettes smoked were not determined. The active sampling system used was housed in a briefcase placed on the respective seat. The mean nicotine concentrations (geometric mean, range) measured were $5.5(0-40.2) \mu \mathrm{g} / \mathrm{m}^{3}$ in the non-smoking section and $9.2(0-112) \mu \mathrm{g} /$ $\mathrm{m}^{3}$ in the smoking section. There was also a significant gradient of rising nicotine concentrations from the non-smoking to the smoking section. The values measured in the different types of aircraft did not vary greatly. Clearly, the differences in the ventilation systems were of no importance in this study. The authors considered these results as proof that separation of smoking and non-smoking sections was effective and that the ventilation system was efficient. Although the authors themselves felt that the calculation of cigarette equivalents was prone to manipulation, they nevertheless stated that exposure had been found to be lower, by orders of magnitude, than that caused by smoking one cigarette.

Comment: In figure 1, the single concentrations measured in the smoking and non-smoking sections have been plotted. It is evident that considerably elevated nicotine concentrations were also present in the non-smoking sections. For further differentiation, the (geometric) means were calculated separately for the middle part of the non-smoking section, the boundary zone (two rows) of the non-smoking section, and the smoking section. The resulting levels deviated from those ascertained by the authors: $1.5,5.2$, and $6.3 \mu \mathrm{g} /$ $m^{3}$, respectively (see table 1). On the basis of these mean levels, two of the nine nicotine values for the non-smoking section (middle) and 26 of the 40 for the boundary zone were above the mean level for the smoking section. The highest nicotine concentrations measured in the non-smoking sections corresponded to approximately six times the mean concentration in the smoking sections.

In 1989, Malmfors et $a l^{5}$ published a study based on 48 European flights in aircraft of the DC 9-21, DC 9-41, and MD 81/83 types. Most of the flights took 1-2 $\mathrm{h}$, although some took $2-3 \mathrm{~h}$. Recirculated air $(23 \%)$ was used only in the cabin of the MD 81/83 type. The theoretical air exchange rate was $33 / \mathrm{h}$ for the DC planes and $22 / \mathrm{h}$ for the MD $81 / 83$ plane. Seats to accommodate the measuring equipment (an active system in a briefcase) were selected at random ie, there was no clustering near the borderline between the smoking and non-smoking sections as in the study by Oldaker and Conrad. ${ }^{4}$ The average number of cigarette butts per passenger per hour in the smoking sections was 1.15 in the business class
Nicotine $\left(\mu \mathrm{g} / \mathrm{m}^{3}\right)$

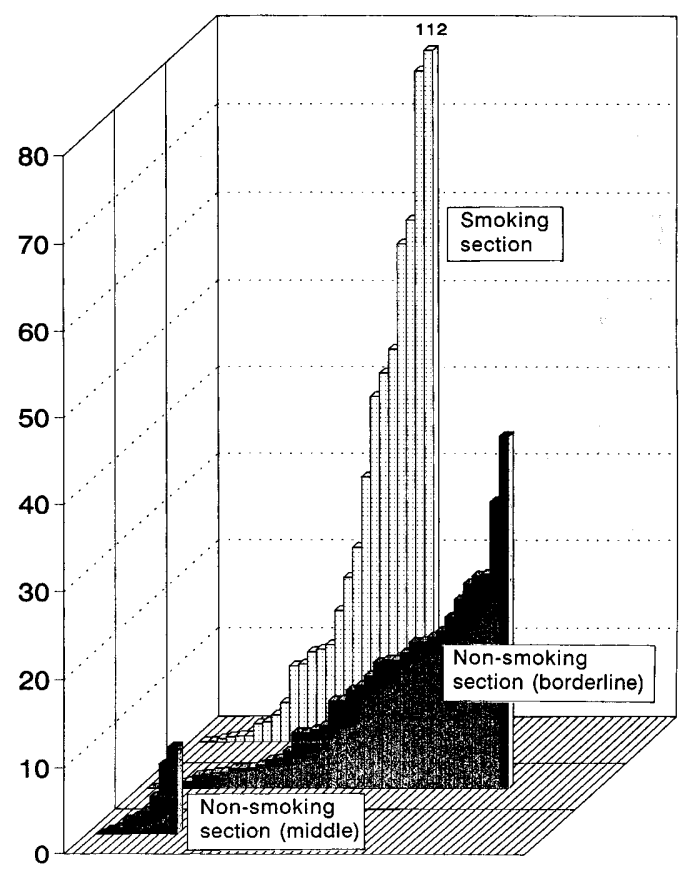

Figure 1 Measurements of nicotine levels in aircraft cabins (data from Oldaker and Conrad ${ }^{4}$ ). Of 40 nicotine values for the non-smoking borderline area (mean $5.2 \mu \mathrm{g}$ / $\left.m^{3}\right) 26$ are above the mean level for the smoking section $\left(6.3 \mu \mathrm{g} / \mathrm{m}^{3}\right)$. Peak values were approximately six times higher than mean levels in the smoking section. In the middle part of the non-smoking section (mean $1.5 \mu \mathrm{g} / \mathrm{m}^{3}$ ) high concentrations were also found (two of nine values exceeded the mean level for the smoking section). (The heights of the bars in this figure are drawn according to the $y$-axis scale except for the tallest bar, whose true height is indicated above the bar.)

and 0.90 in the tourist class section. The concentrations measured are shown in tables 1-3.

According to a regression analysis, the resulting concentrations of nicotine, RSP, and $\mathrm{CO}$ rose with the length of the flight and the number of cigarette butts and dropped with the distance of the sampling sites from the smoking sections. The concentrations measured were mean values for the entire flight (ie, there may well have been higher levels depending on site and time), and sampling took place not in the breathing zone and near the eyes but at a level $40-50 \mathrm{~cm}$ above seat surfaces. When discussing possible health impairment such as local irritation of the eyes (particularly in persons wearing contact lenses) and the mucous membranes in the mouth, the authors drew attention to the possible aggravation of such symptoms by low humidity or ozone.

Comment: The mean nicotine levels were clearly higher than in the above cited study by Oldaker and Conrad, ${ }^{4}$ although the seats had been selected at random and were thus representative of the non-smoking section as a whole. Likewise, the 95th percentile of nicotine values measured in the tourist class non-smoking section corresponded to two-thirds of the 95th percentile in the smoking section. In all sections, CO levels did not differ essentially; nevertheless, the 95th percentiles of more than 2 ppm both in the smoking and non-smoking sections are worthy of 
Table 1 Nicotine concentrations $\left(\mu \mathrm{g} / \mathrm{m}^{3}\right)$ aboard aircraft

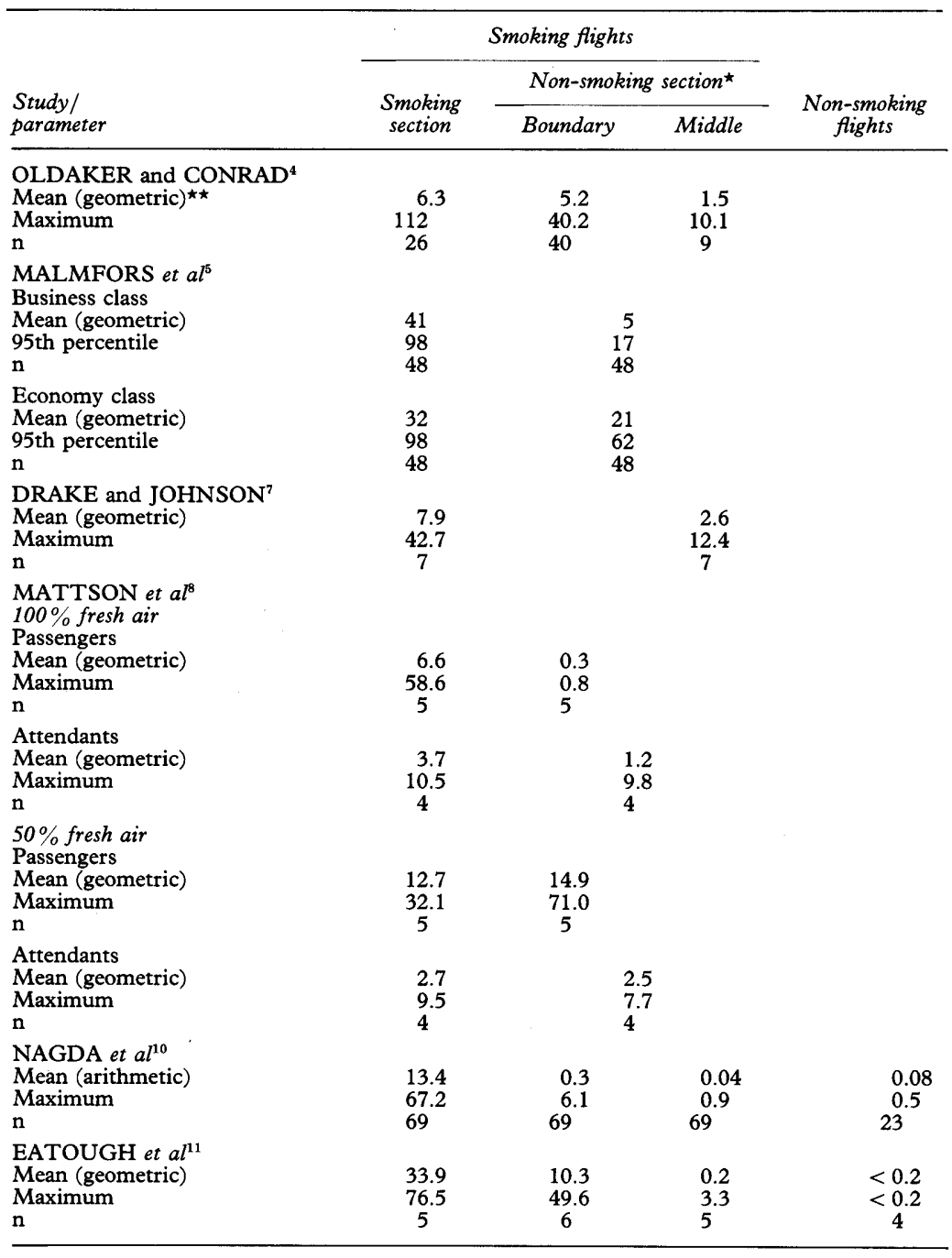

* Definitions of non-smoking section:

Oldaker and Conrad, Eatough et al: borderline area = two rows adjacent to smoking section Nagda et al: borderline area $=$ three rows adjacent to smoking section. Malmfors et al: any seat could be selected. Mattson et al: attendants assigned to work in non-smoking section.

$\star \star$ Several authors found a log-normal distribution of values measured. For this reason, geometric means were given or calculated where possible. In some cases, this may lead to an underestimation if the assumption of a log-normal distribution is not completely true.

Table 2 RSP concentrations $\left(\mu \mathrm{g} / \mathrm{m}^{3}\right)$ aboard aircraft

\begin{tabular}{|c|c|c|c|c|}
\hline \multirow{3}{*}{$\begin{array}{l}\text { Study/ } \\
\text { parameter }\end{array}$} & \multicolumn{3}{|c|}{ Smoking flights } & \multirow{3}{*}{$\begin{array}{l}\text { Non-smoking } \\
\text { flights }\end{array}$} \\
\hline & \multirow{2}{*}{$\begin{array}{l}\text { Smoking } \\
\text { section }\end{array}$} & \multicolumn{2}{|c|}{ Non-smoking section $\star$} & \\
\hline & & Boundary & Middle & \\
\hline \multicolumn{5}{|l|}{$\begin{array}{l}\text { MALMFORS et al. }{ }^{5} \\
\text { Business class }\end{array}$} \\
\hline Mean (geometric) $)^{\star \star}$ & 250 & & & \\
\hline $\begin{array}{l}\text { 95th percentile } \\
\mathrm{n}\end{array}$ & $\begin{array}{r}540 \\
48\end{array}$ & & & \\
\hline \multicolumn{5}{|l|}{ Economy class } \\
\hline Mean (geometric) & 220 & & & \\
\hline 95th percentile & 560 & & & \\
\hline $\mathrm{n}$ & 48 & & & \\
\hline \multicolumn{5}{|c|}{ DRAKE and JOHNSON ${ }^{7}$} \\
\hline Mean (geometric) & 23 & & 7 & \\
\hline Maximum & 185 & & 98 & \\
\hline n & 12 & & 12 & \\
\hline \multicolumn{5}{|l|}{ NAGDA et al. ${ }^{10}$} \\
\hline Mean (geometric) & 177 & 40 & 19 & 11 \\
\hline Maximum & 499 & 180 & 118 & 18 \\
\hline $\mathrm{n}$ & 65 & 63 & 62 & 19 \\
\hline \multicolumn{5}{|l|}{ EATOUGH et al..$^{11}$} \\
\hline Mean (geometric) & 144 & 74 & 35 & 28 \\
\hline Maximum & 203 & 213 & 56 & 35 \\
\hline & 4 & 6 & 5 & 4 \\
\hline
\end{tabular}

For footnotes, see table 1 . note. Weber ${ }^{6}$ advocates measures to protect nonsmokers at levels greater than $1.5 \mathrm{ppm}$ and considers such measures mandatory at levels above $2 \mathrm{ppm}$. In the tourist class, RSP levels measured in the non-smoking section (both mean and 95th percentile) were not much lower than those in the smoking section. Generally, the levels in the non-smoking section of the tourist class were markedly worse than in the non-smoking section of the business class, for all three components measured.

In 1990, Drake and Johnson ${ }^{7}$ published the results of measurements taken some years ago by Philip Morris International and the R J Reynolds Tobacco Company (active sampling system in a briefcase). Measurements were taken during four flights between Tokyo and Hong Kong ( $5 \mathrm{~h}$ ) and between New York and Tokyo (14 h) aboard Boeing 747-100 and 747200 aircraft.

In contrast to the study by Oldaker and Conrad, ${ }^{4}$ primarily seats in non-smoking sections at some distance from the smoking sections were selected. Air was recirculated only within individual ventilation areas which, however, did not always correspond exactly to the smoking and non-smoking sections. The number of cigarettes smoked per hour was between 2 and 77 (mean 23). The parameters measured and the results are shown in tables 1 and 2.

Ten of the 24 nicotine values measured were not included on account of measurement errors. Regression analysis revealed that the levels measured depended on the numbers of cigarettes smoked and that they were higher at the aft than at the front of an area.

Comment: In part, the mean and maximum levels measured in this study were lower than those measured in other studies. This may have been due to the fact that large aircraft of the $B$ 747 type were involved. Forty percent of the nicotine values were unsuitable for evaluation. In evaluating the non-smoking section it should be noted that no measurements were taken in the borderline area.

A study published by Mattson et $a l^{8}$ was conducted with the participation of the US National Cancer Institute, the American Health Foundation, the University of Massachusetts and the US Environmental Protection Agency (EPA). On four flights of approximately $4 \mathrm{~h}$ duration, the personal nicotine exposure of five passengers and four flight attendants was determined with the aid of active samplers worn on the body. In addition, cotinine levels in urine were measured up to $72 \mathrm{~h}$ after the respective flight and the postflight period was monitored for possible tobacco smoke exposure using passive samplers and a diary. Finally, information was obtained on discomfort and health disorders attributable to tobacco smoke by means of a questionnaire distributed before and after each flight. Two flights were operated by Boeing B 727 (100\% fresh air supply) and the other two by B 767 aircraft $(50 \%$ recirculated air). Repeated counting on all flights resulted in a mean 
Table $3 C O$ concentrations ( $p p m)$ aboard aircraft

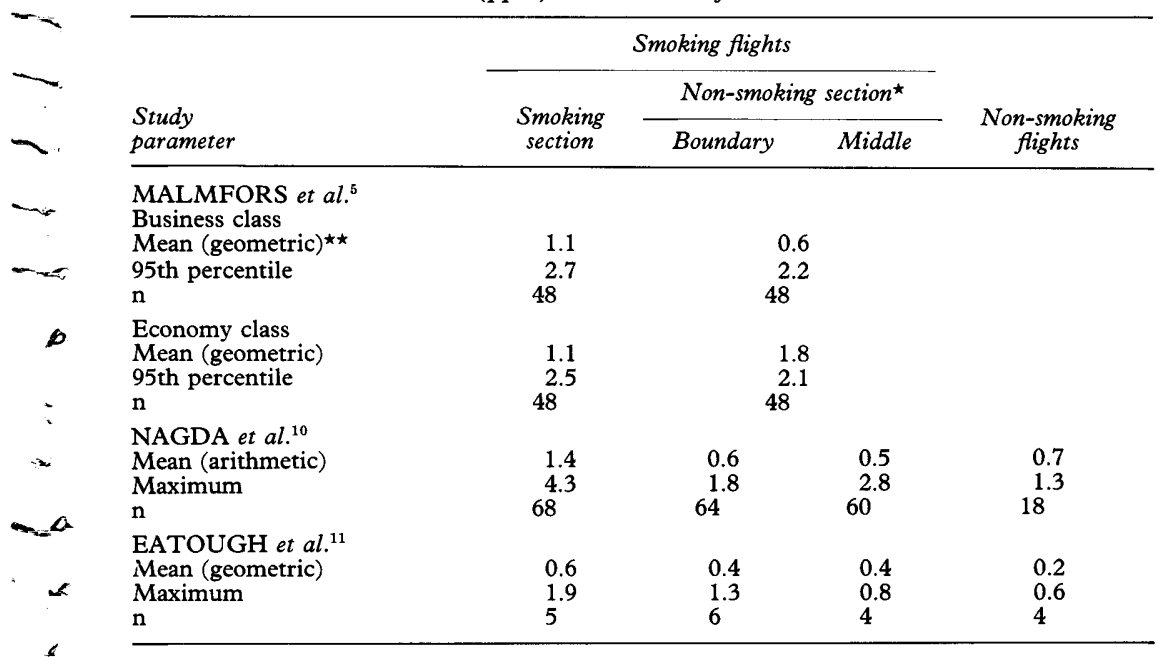

For footnotes, see table 1 .

number of four persons smoking at any one time. Mean and maximal nicotine levels are listed in table 1.

For the evaluation of urine cotinine levels, two exposure groups were formed: "low", with nicotine levels below the median of $5.5 \mu \mathrm{g} / \mathrm{m}^{3}$; and "high", with levels above that figure. When plotting the "moving" $24 \mathrm{~h}$ mean cotinine levels, the resulting curve depicted a rise of the "high" group to about three times the level of the "low" group (not shown). Thus, persons with a high nicotine exposure exhibited high cotinine levels in urine. On account of passive smoke exposure subsequent to the flight, 10 cotinine values were not included in the evaluation.

No correlation could be established between nicotine exposure and symptoms such as dry mouth, coughing, sneezing, sore throat, and headache. Such a correlation was established, however, with regard to eye and nose symptoms, smoke irritation, and subjective perception of smoke.

The authors concluded that complete separation of air between smoking and nonsmoking sections had not been attained on the flights examined. Passenger and cabin crew exposure to tobacco smoke was comparable to that in other closed environments where smoking is permitted and increases the cumulative health risk, and the acute irritation and discomfort experienced by non-smokers subjected to passive smoking.

Comment: In figure 2, all $36(4 \times 9)$ results of nicotine measurements have been depicted. The levels measured in smoking and non-smoking sections did not differ substantially for conditions of $100 \%$ fresh air and $50 \%$ recirculated air supply whereas there were clear differences for the two types of aircraft (and ventilation systems) involved with regard to the levels measured in the border zone of the non-smoking sections. In the case of recirculated air ( $B$ 767), there was no significant difference between the smoking section and the non-smoking borderline area-ie, nonsmokers were exposed to tobacco smoke levels similar to those in the smoking section. In the non-smoking borderline area, single values measured were even higher than in the smoking

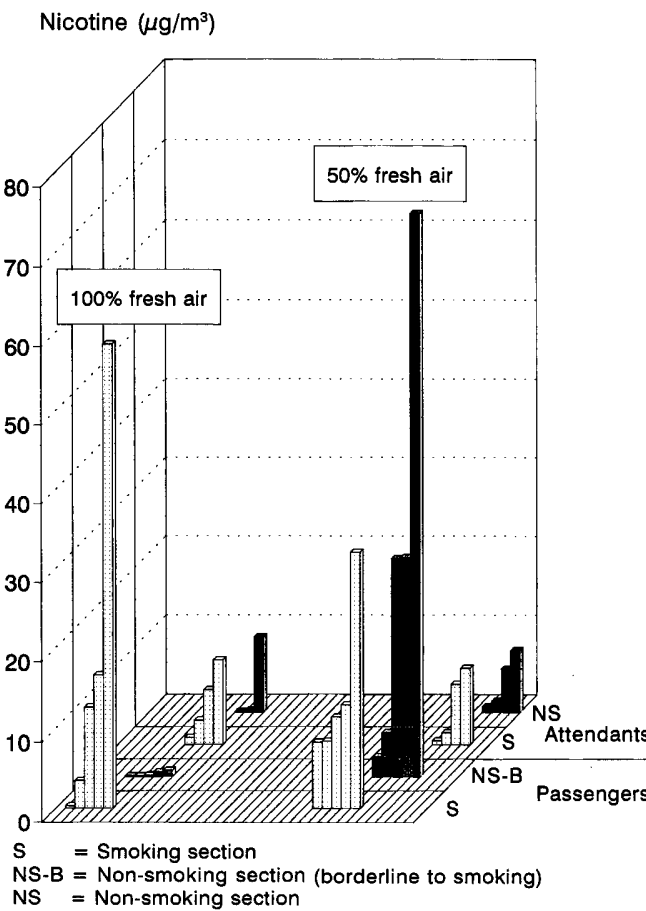

Figure 2 Nicotine measurements in aircraft cabins (data from Mattson et $\mathrm{al}^{8}$ ). Levels in smoking and non-smoking sections did not differ substantially for fresh air proportions of 100 and $50 \%$. In contrast, obvious differences between the two types of aircraft examined (types of ventilation) were recognisable for the borderline part of the nonsmoking section. Under conditions of a $50 \%$ share of fresh air, single values exceeded even those measured in the smoking section.

section. Levels were generally lower for flight attendants than for passengers. This did not depend on either the proportion of recirculated air or the working area (smoking/non-smoking section). With regard to the nicotine intake, however, one should consider the fact that flight attendants at work have a higher respiratory volume than passengers who are resting.

In 1992, Nagda et $a l^{9}$ published the results of measurements which, in addition to the tobacco smoke components considered in this paper, included parameters such as ozone, carbon dioxide, fungi, bacteria, temperature, relative humidity, barometric pressure, and air exchange rate. Their paper summarises the results of a comprehensive study commissioned by the US Department of Transportation $^{10}$ in which measurements were taken on 92 randomly selected flights (including eight international and 23 non-smoking flights) from US airports, using an active sampling system housed in a briefcase. Twelve different types of narrow- and wide-bodied aircraft were studied. Nominal air exchange rates were $10-15 / \mathrm{h}$ for cabins with a $20-50 \%$ proportion of recirculated air and $23-27 / \mathrm{h}$ for cabins with a $100 \%$ fresh air supply. The mean number of cigarettes smoked was 1.5 per smoking-section passenger per hour. Tables 1-3 give arithmetic means and maximum values of tobacco smoke constituents.

Mean nicotine values as measured in the middle of the non-smoking section did not 
differ substantially from those on non-smoking flights whereas they were approximately threefold higher in the three rows bordering the non-smoking section. Maximum levels in the middle of the non-smoking section were twice as high, and in the borderline area 13 times as high, as those for non-smoking flights. Mean and maximum levels for the smoking section were 28 and 140 times higher, respectively, than those for non-smoking flights.

Mean (maximum) particle (RSP) levels (optical method*) as compared to values for non-smoking flights were found to be 17 (47) times higher for the smoking section, four (17) times higher for the non-smoking section (borderline three rows), and two (11) times higher for the non-smoking section (middle).

Mean and maximum carbon monoxide (CO) levels in the non-smoking section during smoking flights were almost twice those measured during non-smoking flights while in the smoking section, mean and maximum $\mathrm{CO}$ levels were approximately three times those measured on non-smoking flights.

The authors summarised their results as follows: particle and nicotine concentrations were highest in the smoking section and were somewhat higher in the boundary region near smoking sections than in other non-smoking sections or on non-smoking flights. Levels of these tobacco smoke components were correlated with smoking rates observed, and their levels in the boundary section were higher the closer the measurements were taken to the smoking section. In the authors' opinion, a ban on smoking aboard aircraft would benefit cabin staff and passengers more than other measures such as increased air circulation rates or more effective air filtration. They were not convinced of the advantages of a 10-minute lifting of the ban every $2 \mathrm{~h}$. Although this approach would clearly reduce exposure during the nonsmoking period, it could substantially increase the health risks of acute exposure during the brief periods when smoking would be permitted.

Comment: This study has been particularly useful as it included non-smoking fights and thus provided comparative values in the absence of tobacco smoke but in an otherwise identical situation. The values measured during smoking fights were not broken down by type of aircraft or type of ventilation, although this would have been desirable for a more differentiated comparison with the results of other studies. In their final report to the US Department of Transportation, Nagda et $\mathrm{al}^{10}$ presented risk assessments based on the RSP values measured, flight frequency and duration, proportion of time spent in different sections of the cabin, respiratory rate, two different dose-response models for the relationship between environmental tobacco smoke

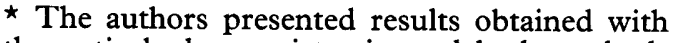
the optical, the gravimetric, and both methods taken together. Since most data were given for the optical method and there was a better correlation with smoking rates and nicotine levels, values obtained with the optical method are cited here.
(ETS) and lung cancer deaths, and several further assumptions. The estimated lifetime lung cancer risk due to ETS exposure for non-smoking cabin crew members is about 13 premature lung cancer deaths per 100000; for non-smoking "business passengers", 0.6; and for "casual passengers", 0.1 premature lung cancer deaths per 100000. Using the RSP values measured by Eatough et $\mathrm{al}^{11}$ the respective figures would be 16, 1 , and 0.2. If the fairly high RSP values from the Malmfors study $y^{5}$ are used for these calculations, the respective figures would be 70,7 , and 1.3 premature lung cancer deaths per 100000 .

In 1992, Eatough et $a l^{11}$ reported on measurements taken on four DC-10 flights each of $5 \mathrm{~h}$ duration. The results had already been presented at two congresses held in 1990. A total of six measurements in the smoking section and 11 in the non-smoking section (six in the two rows bordering the smoking section) were taken. In addition to nicotine, RSP, and CO, the levels of other tobacco smoke components were determined, using an active sampling system (briefcase). Background levels were also established during four smoke-free flights of identical duration. The DC-10 aircraft cabin has a nominal air exchange rate of $30 / \mathrm{h}$, with no air recirculation. During the four flights, $32,76,115$, and 218 cigarettes each were smoked.

Tables 1-3 show that, for all three constituents, (geometric) means as well as maximum values exhibited a similar drop in levels from the smoking section to the two borderline rows, the middle of the non-smoking section, and the cabin during non-smoking flights as described by Nagda et al. ${ }^{9}$ Nicotine levels determined by Eatough et al were considerably higher than those found by Nagda et al, whereas the CO levels were clearly lower. Compared to the Nagda study, Eatough's RSP levels were somewhat lower in the smoking section, but they were twice as high in the nonsmoking section.

Comment: Eatough et $\mathrm{al}^{11}$ concluded that exposure calculations based only on nicotine will underestimate total exposure since nicotine is removed from cabin surfaces at faster rates than other tobacco smoke constituents. On the other hand, it should be noted that the RSP and CO levels measured may include sources other than tobacco smoke. This overestimation may be corrected by considering background measurements (eg, measurements taken on non-smoking flights).

\section{Tobacco smoke in other indoor situations}

In addition to the studies described above which refer to measurements in aircraft cabins, other studies have reported on tobacco smoke measurements in other settings.

Muramatsu et $a l,{ }^{12}$ who used personal active samplers in Japan, recorded mean nicotine concentrations of $6-20 \mu \mathrm{g} / \mathrm{m}^{3}$ in air-conditioned offices; $7 \mu \mathrm{g} / \mathrm{m}^{3}$ in homes; $15 \mu \mathrm{g} / \mathrm{m}^{3}$ in restaurants; $32-43 \mu \mathrm{g} / \mathrm{m}^{3}$ in cafés, bars, and cars; 16.7 and $13.5 \mu \mathrm{g} / \mathrm{m}^{3}$, respectively, above 
seats in smoking sections of trains and passenger aircraft, and 1.3 and $5.3 \mu \mathrm{g} / \mathrm{m}^{3}$, respectively, in non-smoking sections of trains and passenger aircraft. Maximum levels measured above seats in smoking sections of trains and passenger aircraft were 49 and $29 \mu \mathrm{g} / \mathrm{m}^{3}$, respectively.

Eudy et $a l^{13}$ used a stationary sampler in a restaurant in North Carolina (US) and recorded nicotine levels (mean level, range) of $2.1(0.3-11.5) \mu \mathrm{g} / \mathrm{m}^{3}$, RSP levels of 29.3 $(0-105) \mu \mathrm{g} / \mathrm{m}^{3}$, and CO levels of $4(0-16) \mathrm{ppm}$.

Using a portable sampler, Proctor ${ }^{14}$ found the "typical" levels shown in table 4 before and after introduction of a smoking ban in the London Underground system.

McCarthy et $a l^{15}$ performed measurements using active personal samplers worn by children in Massachusetts, USA. The resulting exposure levels (mean, range) in non-smoking families were $0.3(0-1.0) \mu \mathrm{g} / \mathrm{m}^{3}$ for nicotine and $29.4(21.6-39.8) \mu \mathrm{g} / \mathrm{m}^{3}$ for RSP; in families with smokers the levels were $2.5(0.1-12.0)$ $\mu \mathrm{g} / \mathrm{m}^{3}$ for nicotine and $56.2(18.0-116) \mu \mathrm{g} / \mathrm{m}^{3}$ for RSP.

Klus et $a l^{16}$ measured a nicotine level of less than $1 \mu \mathrm{g} / \mathrm{m}^{3}$ in a four-person non-smoking household in Hamburg, Germany. The level rose to $14-16 \mu \mathrm{g} / \mathrm{m}^{3}$ after $10-11$ cigarettes had been smoked within a 4 -h period. In the nonsmoking area of a restaurant, the authors measured a level of less than $1 \mu \mathrm{g} / \mathrm{m}^{3}$, a level of $2-4 \mu \mathrm{g} / \mathrm{m}^{3}$ after 3-5 cigarettes were smoked in a period of $3 \mathrm{~h}$, and $6 \mu \mathrm{g} / \mathrm{m}^{3}$ nicotine after 20 cigarettes were smoked within a 4 -h period.

In addition to the studies reviewed above, which primarily involved measurement of tobacco smoke in aircraft cabins and other closed environments, other publications have evaluated such conditions.

\section{"Committee" evaluation}

In 1986, a comprehensive report was published by the 11 experts who formed the Committee on Airliner Cabin Air Quality of the US National Research Council. ${ }^{17}$ This report examined different aspects of air quality and safety aboard passenger aircraft. On the subject of tobacco smoke it had the following to report.

Although in many public places, smoking has been banned, there are no legal limits for tobacco smoke in the US. Occupational and ambient air standards for CO and RSP, which have often been applied to tobacco smoke, do not take into consideration other toxic components of tobacco smoke including many known

Table 4 Measurements of tobacco smoke ingredients in London Underground trains prior to and after introduction of a ban on smoking (after Proctor ${ }^{14}$ )

\begin{tabular}{lccc}
\hline Compartment & Nicotine $\left(\mu \mathrm{g} / \mathrm{m}^{3}\right)$ & $R S P\left(\mu \mathrm{g} / \mathrm{m}^{3}\right)$ & $C O(p p m)$ \\
\hline $\begin{array}{l}\text { Smoking } \\
\text { (before ban) }\end{array}$ & 32 & 630 & 3.5 \\
$\begin{array}{l}\text { Non-smoking } \\
\text { (before ban) }\end{array}$ & $(16-74)$ & & \\
(after ban) & 7 & 180 & 3 \\
\hline
\end{tabular}

Figures given represent "typical" levels; figures in brackets represent ranges. carcinogens and cocarcinogens. In Japan, the indoor air standard for particulate matter in office buildings is $150 \mu \mathrm{g} / \mathrm{m}^{3}$. This level would be exceeded by most of the measurements taken aboard passenger aircraft. It is the purpose of ventilation standards for smoking areas in public buildings to ensure that the majority $(80 \%)$ of persons have a feeling of well-being. Ventilation aboard aircraft does not meet this criterion when non-smokers are compelled to work or wait in a smoking section or to pass through it.

Aboard passenger aircraft, the persons most exposed are the flight attendants who are regularly exposed to tobacco smoke. In some types of aircraft, the galley is located within the smoking section, so that cabin staff are exposed to smoke with the same intensity and for the same period of time as passengers seated in the smoking section. Passengers are not exposed to aircraft tobacco smoke on a daily basis. Nevertheless, non-smoking passengers (eg children) seated in the smoking section suffer exposure. Passengers seated in rows of the non-smoking section close to the smoking section are probably exposed to the next highest concentrations.

The total exposure for a flight attendant who works in the smoking section is equivalent to that of a person living with a smoker consuming one pack of cigarettes per day. For this reason, the health risk for flight attendants may be comparable to that for spouses of smokers.

The Committee members concluded that tobacco smoke concentration is directly proportional to the intensity of the source (number of smokers) and inversely proportional to the fresh air supply in a smoking section. Recirculation of air in its various versions will affect the distribution of smoke. It does not, however, fundamentally change the relationship between the generation of smoke and the balance of the total pollutants in the cabin. The filters currently used remove particulate matter only and not gaseous components of tobacco smoke. Particulates are also absorbed to a certain degree by cabin wall linings and seats.

The Committee considered a number of ways to reduce tobacco smoke aboard passenger aircraft. For economic reasons, solutions which require technical modifications such as increased air exchange rates, relocation of toilets and galleys, and separation of smoking sections by solid partitions, are scarcely feasible. Although reversion to a system of random distribution of smokers throughout the entire cabin would reduce peak concentrations of pollutants, this would be unacceptable for the majority of passengers.

The Committee proposed a ban on all domestic flights for four principal reasons: 1) to reduce irritation and discomfort to passengers and cabin crew, 2) to reduce potential health hazards for cabin staff from tobacco smoke, 3) to eliminate the risk of fire from cigarettes, and 4) to raise the quality of cabin air to meet standards for indoor air in other situations. An additional benefit of the ban on smoking would be a reduction of cleaning costs. The Committee acknowledged that some 
habitual smokers may experience withdrawal symptoms during flights longer than $3 \mathrm{~h}$; however, it attached greater importance to the potential health hazards of passive smoking, which affect more people than do withdrawal symptoms.

\section{Evaluation by other authors}

In response to the publication by Oldaker and Conrad $^{4}$, Repace and Lowrey ${ }^{18}$ concluded that, if converted to RSP values, the nicotine concentrations measured by Oldaker and Conrad would be higher than those measured in restaurants. One quarter of the levels measured in non-smoking sections of passenger aircraft would be equal to or higher than those measured in smoking areas of restaurants. Thus, a division of aircraft cabins into smoking and non-smoking sections would not seem to offer adequate protection to non-smokers against high pollutant concentrations. Such separation would reduce but not eliminate exposure.

In 1988, Holcomb $^{19}$ reviewed the studies available and concluded that the current scientific evidence would not justify a ban on smoking in aircraft cabins. The results recorded in smoking sections revealed low concentrations of substances attributable to tobacco smoke. In non-smoking sections, concentrations were even lower and thus, in Holcomb's view, would support the efficiency of measures taken so far-ie, separation of smokers and non-smokers. According to Holcomb, the available data pointed to factors and substances other than tobacco smoke that may lead to complaints by passengers and cabin crew. Finally, the author stated that exposure to tobacco smoke was unlikely to cause detrimental effects on health even in cases of compromised individuals and cabin staff because exposure was limited and intermittent.

Crawford ${ }^{20}$ reviewed the situation in 1989 and concluded that the very high air exchange rates $(18-25 / h)$ would effectively control any pollution present in passenger aircraft cabins. The availability of smoking and non-smoking sections met passengers' demands. The available studies and reviews did not support the hypothesis that exposure to tobacco smoke aboard passenger aircraft would constitute a health risk for cabin crew or passengers. Other factors cause subjective complaints. Current scientific and medical knowledge did not substantiate a ban on smoking aboard passenger aircraft, according to Crawford, and further research was needed.

In 1991, at the instigation of the Commission of the European Communities, the European Bureau for Action on Smoking Prevention (BASP) published a booklet in three languages $^{21}$, examining many aspects of smoking aboard aircraft and listing a considerable number of airlines which operate non-smoking flights.

In a letter to the editor of the New England Fournal of Medicine, Ershler ${ }^{22}$ proposed the introduction of the smoke-appreciation time (SAT). He observed that, depending on the distance from the smoking section, it took from $1-5$ seconds (1-3 rows) up to 30 seconds (15 and more rows) after switching off the "No smoking" sign before smoke was perceived. He could not detect differences between airlines but generally found conditions to be better in large aircraft such as DC-10 or B 747 . His proposals included disclosure of SAT scores at the time of booking so that customers concerned about health hazards from passive smoking could select seats with the best ratings. Seats with bad SAT scores could be offered at reduced rates.

\section{Survey results}

Finally, the results of several airline surveys are worth noting. In 1990, Lufthansa conducted a passenger survey on "Smoking Aboard". ${ }^{23}$ The survey showed that $82 \%$ of all passengers interviewed and $92 \%$ of nonsmokers were annoyed by tobacco smoke. In 1981, Scandinavian Airlines conducted a survey among cabin staff $^{24}$ to establish how 12 adverse factors hampered their work. Four percent did not feel annoyed by tobacco smoke, $26 \%$ felt annoyed to a certain degree, and $69 \%$ to a high degree; tobacco smoke ranked first among the annoyance factors. ${ }^{24}$ In $1992,90 \%$ of Lufthansa cabin staff interviewed favoured a ban on smoking aboard aircraft. ${ }^{25}$ In a survey of 585 female flight attendants from 10 Asian countries, $81 \%$ believed that passive smoking is harmful (including $85 \%$ of current smokers). ${ }^{26}$

\section{Summary and conclusions}

Being seated in the non-smoking section of an aircraft cabin does not provide adequate protection against involuntary inhalation of tobacco smoke. Even at some distance from the smoking section, single concentrations may reach levels similar to average levels in the smoking section. Especially in the borderline area (ie, in the first two or three rows adjacent to a smoking section), levels may be equal to or even exceed those found in the smoking section. This is particularly true of those instances where air is partially recirculated.

In any evaluation of measurements in the non-smoking section, it is important to know whether sampling was preferentially performed: 1) in the rows adjacent to the smoking section $\left.^{4} ; 2\right)$ at random over all seats ${ }^{5} ; 3$ ) exclusively at seats outside the borderline $\operatorname{area}^{7}$; or 4) at defined sites (middle, border zone). ${ }^{8,9,11}$

Tobacco-associated pollutant concentrations in smoking sections and parts of nonsmoking sections bordering the smoking sections of passenger aircraft in part clearly exceed those measured in other indoor situations where smoking takes place. Levels in the nonsmoking sections of aircraft (beyond the areas bordering smoking sections) are similar to those in homes where smoking takes place. In the majority of studies, health risks associated with passive smoking were detected in persons living in households with smokers. 
Table 5 Distribution of seats in Boeing 737-300 aircraft (see also figure 3)

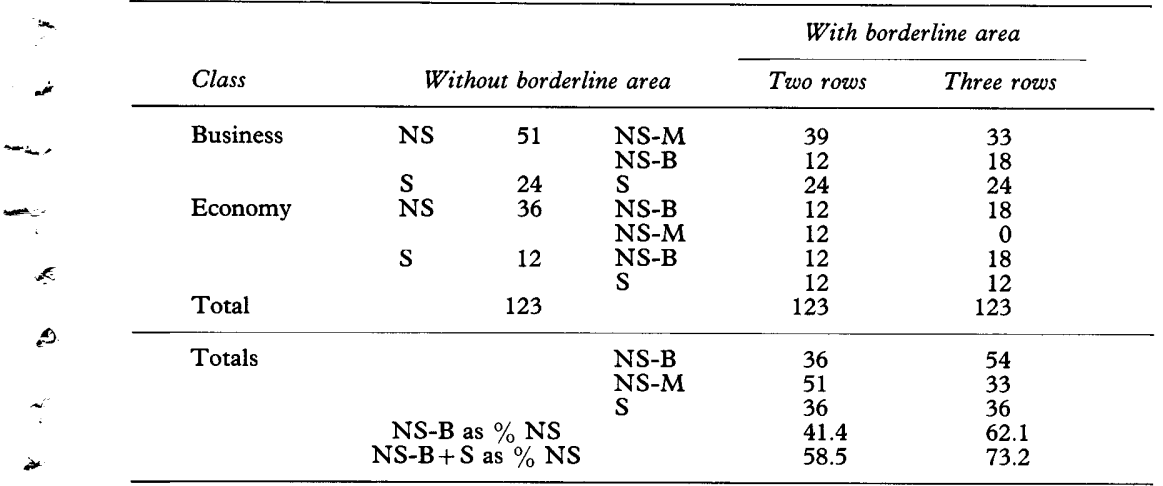

Abbreviations: $\mathrm{S}=$ smoking section; NS-B = non-smoking section (borderline area); NS-M $=$ non-smoking section (middle).
Lower nicotine and RSP values were measured in certain types of aircraft (eg, B 747) or in some non-smoking sections in the front part of the cabin (first class, business class). These levels varied, however, depending on the number of cigarettes consumed in the respective smoking sections. Were ventilation truly effective, it should result in consistently low levels irrespective of the number of cigarettes smoked.

In some of the studies reviewed, ${ }^{3,8}$ tobaccorelated parameters were measured in blood and/or urine, demonstrating that tobacco smoke is not just present in cabin air but is, in fact, inhaled by passengers and flight attendants. Tobacco smoke components have been detected in body fluids and have been found to correlate with tobacco smoke levels in cabin air.

The risk of chronic respiratory disease or lung cancer from passive smoking aboard aircraft is low for average passengers given their normally short exposure period. However, this exposure should still be eliminated because it contributes to their total exposure to ETS, a documented human carcinogen.

For frequent flyers and flight attendants the health risk from passive smoking aboard aircraft is comparable to that encountered by persons consistently exposed to tobacco smoke at home or at the workplace. The risk level is determined by the duration and level of exposure in the smoking and/or non-smoking sections. Adverse effects will be highest for non-smokers seated in the smoking section (ie, persons accompanying smokers, waiting-listed passengers who could only get a seat in the smoking section, and flight attendants).

Acute effects of tobacco smoke exposure in the non-smoking section are more likely to occur, even after short-term exposure. In particular, the concentrations measured in the two or three rows adjacent to the smoking section may produce irritation of the eyes and the respiratory tract and discomfort. Children, pregnant women and persons highly sensitive to tobacco smoke should avoid such exposure. Both acute and chronic exposure to cigarette smoke produce a variety of health effects. ${ }^{27-29}$ "Passive smoking at the workplace" has been specifically mentioned as a group of potential carcinogens in the German MAK List in

\section{Boeing 737-300}

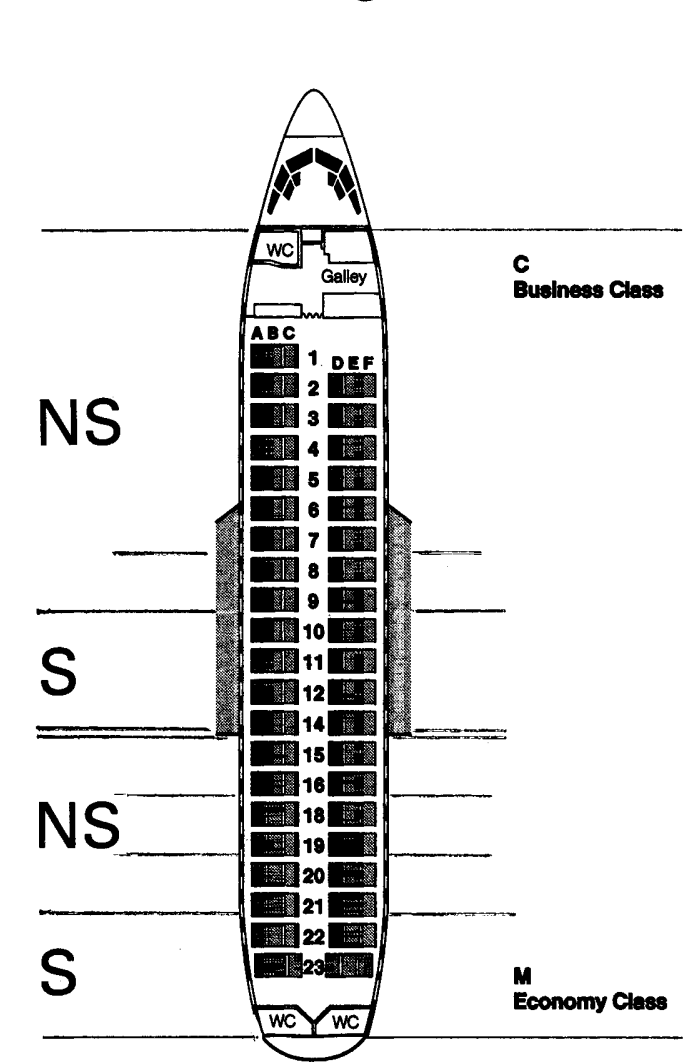

Figure 3 Distribution of seats in Boeing 737-300 aircraft (see also table 5)

$1985 .^{30,31}$ The US National Institute for Occupational Safety and Health and the US EPA have classified ETS as a potential carcinogen. ${ }^{32,33}$

The practical implications of the results of this evaluation for domestic flights in Germany are shown in table 5 and figure 3. More than $90 \%$ of all domestic flights are operated by Lufthansa. The Boeing 737-300 is by far the most frequently used type of aircraft. Taking two (or three) rows of the non-smoking sections adjacent to the smoking sections as the borderline area, 41 (62) \% seats in the nonsmoking sections $(59(73) \%$ of all 123 seats if the smoking sections are included) aboard this type of aircraft would be unacceptable for nonsmokers. If three rows are taken as the borderline area, not a single seat could be classified as being in a low-exposure area (middle of non-smoking section) in economy class.

Numerous airlines operating abroad and no less than three (smaller companies) operating in Germany have resolved the problem by introducing non-smoking flights. This is the best and least expensive means of protecting non-smokers from passive smoking.

1 US Federal Aviation Administration and US National Institute for Occupational Safety and Health. Health aspects of smoking in transport aircraft. Cincinnati, Ohio: National Institute for Occupational Safety and Health, 1971.

2 Vieillefond H, Fourn P, Auffret R. Characteristics in the atmosphere of long-range transport aircraft cabins. Aviat atmosphe Environ Med 1977; 48: 503-7.
Space 
3 Foliart D, Benowitz NL, Becker CE. Passive absorption of nicotine in airline flight attendants. $N$ Engl $\mathscr{f}$ Med 1983; 308: 1105

4 Oldaker GB, Conrad FC. Estimation of effect of environmental tobacco smoke on air quality within passenger cabins of commercial aircraft. Environ Sci Technol 1987; 21: 994-9.

5 Malmfors $\mathrm{T}$, Thorburn $\mathrm{D}$, Westlin A. Air quality in passenger cabins of DC-9 and MD-80 aircraft. Environ Tech Lett 1989; 10: 613-28.

6 Weber A. Lüftungsmaßnahmen zum Schutze der Passivraucher. Haustechnik-Bauphysik-UmwelttechnikGesundheits-Ingenieur 1983; 104: 37-42

Gesundheits-Ingenieur 1983; 104: $37-42$.
7 Drake JW, Johnson DE. Measurements of certain environmental tobacco smoke components on long-range flights. Aviat Space Environ Med 1990; 61: 531-42.

8 Mattson ME, Boyd G, Byar D, et al. Passive smoking on commercial airline flights. $\mathcal{F} A M A$ 1989; 261 : 867-72. flights. F $A M A$ 1989; 261: 867-72.

9 Nagda NL, Koontz MD, Konheim AG, Hammond SK. Measurement of cabin air quality aboard commercial airliners. Atmos Environ 1992; 26 A: 2203-10.

10 Nagda NL, Fortmann RC, Koontz MD, Baker SR, Ginevan ME. Airliner cabin environment: contaminant measurements, health risks, and mitigation options. Washington, DC: Report No DOT-P-15-89-5, US Dept. of Transportation, 1989.

11 Eatough DJ, Caka FM, Crawford J, Braithwaite S, Hansen LD, Lewis EA. Environmental tobacco smoke in commercial aircraft. Atmos Environ 1992; 26A: 2211-8.

12 Muramatsu M, Umemura S, Fukui J, Arai T, Kira S. Estimation of personal exposure to ambient nicotine in daily environment. Int Arch Occup Environ Health 1987; 59: 545-50.

13 Eudy L, Heavner D, Stancill M, Simmons JS, McConnell B. Measurement of selected constituents of environmental tobacco smoke in a Winston-Salem, North Carolina restaurant. In: Seifert B, Esdorn H, Fischer M, Rüden H, Wegner J. Indoor Air '87, Vol II. Berlin: Institute for Water, Soil and Air Hygiene, 1987, pp 126-30.

14 Proctor C. A study of the atmosphere in London underground trains before and after the ban on smoking. Toxicol Lett 1987; 35: 131-4.

15 McCarthy J, Spengler J, Chang B-H, Coultas D, Samet J. A personal monitoring study to assess exposure to environmental tobacco smoke. In: Seifert B, Esdorn $\mathrm{H}$, Fischer M, Rüden H, Wegner J. Indoor Air' '87, Vol II. Berlin: Institute for Water, Soil and Air Hygiene, 1987, pp 142-6.

16 Klus $H$, Begutter $H$, Ball $M$, Intorp $M$. Environmental tobacco smoke in real life situations. In: Seifert $B$, Esdorn $\mathrm{H}$, Fischer M, Rüden H, Wegner J. Indoor Air', 77 , Vol II. Berlin: Institute for Water, Soil and Air Hygiene, 1987, pp 137-41.

17 National Research Council, Committee on Airliner Cabin Air Quality, Board on Environmental Studies and Toxicology, Commission on Life Sciences. The airliner cabin environment: air quality and safety. Washington,
DC: National Academy Press, 1986 .
18 Repace JL, Lowrey AM. Comment on Lit. No. (4). Environ Sci Technol 1988; 22: 1238-40.

19 Holcomb LC. Impact of environmental tobacco smoke on airline cabin air quality. Environ Tech Lett 1988; 9: 509-14.

20 Crawford WA. Environmental tobacco smoke in airliners health issues. Aerospace, July 1989, 12-7.

21 European Bureau for Action on Smoking Prevention (ed) Let's fly smoke-free-Et si on volait sans fumer? Kein Rauchen auf Flügen. Brussels, Belgium: BASP, 1991.

22 Ershler WB. Passive smoking on commercial airplanes. $N$ Engl $\mathcal{F}$ Med 9 April 1987, 952.

23 Deutsche Lufthansa AG: Ergebnisse der Lufthansa Fluggastbefragung zum Thema "Innerdeutsche Nichtraucherflüge", 23 August 1990.

24 Östberg, O, 'Mills-Orring R. Cabin attendants' working environment - a questionnaire study. Technical Repor No 1980: 74 T. Lulea: Dept of Human Work Sciences, University of Lulea, 1980 (in Swedish).

25 Nichtraucherinitiative Deutschland. Fliegendes Personal der Lufthansa für Rauchverbot in Flugzeugen. Nichtraucher-Info 1992;8 (4)

$26 \mathrm{Li} \mathrm{C}$, Fielding R, Marcoolyn G, Wong CM, Hedley A Smoking behaviour among female airline cabin crew from ten Asian countries. Tobacco Control 1994; 3 : from

27 US Department of Health and Human Services. The health consequences of involuntary smoking. A report of the Surgeon General, 1986. Washington, DC: US Department of Health and Human Services, Public Health Service, Centers for Disease Control, 1986. (DHHS Publication No (CDC) 87-8398.)

28 National Research Council, Committee on Passive Smoking, Board on Environmental Studies and Toxicology. Environmental tobacco smoke. Measuring exposures and assessing health effects. Washington, DC: National Academy Press, 1986.

29 Wald NJ, Booth C, Doll R, et al (eds) Passive smoking health hazard. London, UK: Imperial Cancer Research health hazard. London, UK: Imperial Cancer

30 Henschler D. Deutsche Forschungsgemeinschaft (Hrsg). Passivrauchen am Arbeitsplatz. Senatskommission zur Prüfung gesundheitsschädlicher Arbeitsstoffe. Weinheim: VCH Verlagsgesellschaft, 1985.

31 Deutsche Forschungsgemeinschaft (Hrsg.). Maximale Arbeitsplatzkonzentrationen und Biologische Arbeitsstofftoleranzwerte 1985. Mitteilung XXI der Senatskommission zur Prüfung gesundheitsschädlicher Arbeitsstoffe. Weinheim: VCH Verlagsgesellschaft, 1985.

32 National Institute for Occupational Safety and Health (NIOSH) Environmental tobacco smoke in the workplacelung cancer and other health effects. NIOSH Current Intelligence Bulletin 54, Cincinnati, Ohio: US Department of Health and Human Services, June 1991.

33 US Environmental Protection Agency. Respiratory health effects of passive smoking: lung cancer and other disorders. Washington DC: Office of Research and Development and Office of Air and Radiation, 1992. (Publication No EPA/600/6-90/006F.) 